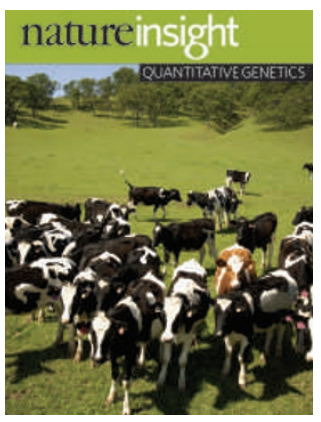

Cover illustration

Animal coat colour

is a complex trait

resulting from small

contributions from many

genes. (Image courtesy

of P. Schermeister/

Photolibrary.com.

Artwork by N. Spencer)

\section{Editor, Nature}

Philip Campbell

Publishing

Nick Campbell

Samia Burridge

Claudia Banks

Insights Editor

Lesley Anson

Production Editor

Davina Dadley-Moore

Senior Art Editor

Martin Harrison

Art Editor

Nik Spencer

Sponsorship

Amélie Pequignot

Production

Jocelyn Hilton

Marketing

Elena Woodstock

Emily Elkins

Editorial Assistant

Alison McGill

\title{
QUANTITATIVE GENETICS
}

\section{PROGRESS}

720 Next-generation genetics in plants

M. Nordborg \& D. Weigel

high degree of improbability". The truth in this is evident just from looking at evolutionary history the improbable happens all the time. It is made possible by large reservoirs of genetic variation, the occurrence of mutations, and interactions between genes and the environment. Recent revolutions in genomics have allowed genetic variation to be described at an unprecedented level, pinpointing nucleotide changes that directly or indirectly affect phenotype. The result is a renaissance in quantitative genetics, particularly in the study of complex traits, enabling theories to be tested by experiment on a genome-wide scale.

One now common approach for examining complex traits in humans is the genome-wide association study, which compares variation across the genomes of two groups of individuals and looks for markers that are associated more with one group than the other, a strategy now being applied to plants and other organisms. After the variants linked to a trait have been identified by such approaches, the effects of these variants on the molecular networks (such as gene expression) in a cell or organism can be investigated. This Insight highlights progress in teasing apart the basis of complex traits in this way, as well as in determining the relative contributions of genetics and the environment to traits in various organisms, from plants to mice to the trio of the malaria parasite, its mosquito vector and the human host.

Genetics has always been a field in which studies in one organism are crucial for discoveries in another, and we hope that the articles in this Insight inspire crosstalk between specialists, as well as entice scientists from other fields. We are pleased to acknowledge the financial support of Monsanto, which contributed towards the distribution of this Insight. As always, Nature carries sole responsibility for editorial content and peer review.

\section{Chris Gunter, Consultant Editor}

724 Applying mouse complex-trait resources to behavioural genetics

J. Flint \& R. Mott

\section{COMMENTARIES}

728 Progress and challenges in genome-wide association studies in humans

P. Donnelly

732 A global network for investigating the genomic epidemiology of malaria

The Malaria Genomic Epidemiology Network

\section{REVIEW}

738 Reverse engineering the genotype-phenotype map with natural genetic variation M. V. Rockman

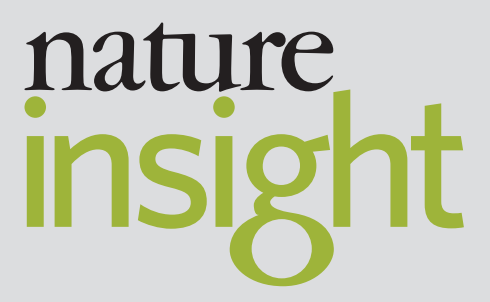

